\title{
Análise da rugosidade radicular após uso de instrumentos manuais, vibratórios e rotatórios. Estudo in vitro
}

\author{
Analysis of root roughness after the use of rotating, vibratory and hand tools. An in vitro study \\ Eleonora de Oliveira Bandolin Martins: \\ Mestre e Doutora em Periodontia pela FOP-UNICAMP, \\ Professora Titular de Periodontia na Universidade Tiradentes-SE. \\ FÁBIO MARTINS \\ Mestre e Doutor em Materiais Dentários pela FOP-UNICAMP, \\ Professor Titular de Prótese na UFS-SE.
}

\begin{abstract}
RESUMO
Introdução: O papel real da rugosidade residual da superfície dental na doença periodontal ainda está sem uma resposta efetiva. Sabemos que a superfície mais rugosa permite maior acúmulo de biofilme, mas também pode facilitar a agregação das células no processo de reparo tecidual na região subgengival. Porém pouco se sabe sobre qual grau de rugosidade é gerado com o uso dos diversos instrumentos periodontais. Objetivo: O objetivo deste estudo foi avaliar a rugosidade gerada pelo uso de cureta manual, ultrassom e ponta diamantada extrafina em caneta de alta e baixa rotação na superfície radicular. Material e Métodos: Foram utilizados para este estudo quarenta dentes humanos extraídos. Os dentes foram limpos e inclusos em cilindros de PVC com resina acrílica. Em seguida, sofreram procedimentos de polimento. Os dentes foram divididos aleatoriamente em quatro grupos, sendo um sem instrumentação e os outros três instrumentados com os aparelhos citados anteriormente. A análise rugosimétrica foi realizada com uso de rugosímetro. Fotomicrografias em microscopia eletrônica de varredura (MEV) foram feitas somente para ilustração. Resultado: A análise estatística dos dados mostrou que o uso de ponta diamantada extrafina produziu o menor grau de rugosidade residual, seguido do uso de curetas manuais e, por último, o uso de aparelho de ultrassom. Conclusão: Não há necessidade de alisamento radicular com uso de curetas manuais após uso de pontas diamantadas extrafinas. Entretanto, há necessidade de alisamento radicular com curetas manuais após o uso de aparelho de ultrassom.
\end{abstract}

Palavras-chave: Topografia; InstrumentaÇÃo; PeriodontiA; Microscopia Eletrônica de VarRedura.

\begin{abstract}
Introduction: The actual role of residual roughness of tooth surface in periodontal disease has still no effective response. We know that rougher surfaces allow greater biofilm accumulation, but they can also facilitate the aggregation of cells in the tissue repair process in the sub-gingival region. But little is known about the degree of roughness generated by the use of the several periodontal instruments. Objective: The aim of this study was to evaluate the roughness generated by the use of hand curettes, by ultrasound, and by extra-fine diamond tips in high and low rotation pens on the root surface. Material and methods: Forty extracted human teeth were used in this study. The teeth were cleaned and enclosed in PVC cylinders with acrylic resin. They were then subjected to polishing procedures. The teeth were randomly divided into four groups, one without instrumentation and the other three were subjected to the above mentioned instruments. Roughness was analyzed with a roughness tester. Photomicrographs and scanning electron microscopy (SEM) were done for illustration purposes. Results: Statistical analysis of data showed that the use of extra-fine diamond tips produced the least residual roughness, followed by the use of hand curettes and lastly, the use of the ultrasound device. Conclusion: There is no need of root planning with hand curettes after using extra fine diamond tips. However, root planning is needed with hand curette after the use of an ultrasound device.
\end{abstract}

Keywords: Topography; Instrumentation; Periodontics; Scanning Electron Microscopy. 


\section{INTRODUÇÃO E REVISÃO DA LITERATURA}

A principal etiologia da doença periodontal é o biofilme bacteriano, e o aumento da rugosidade radicular no acúmulo deste biofilme e cálculo na superfície dental está bem definido, promovendo um aumento do acúmulo de detritos nesta superfície. ${ }^{1}$ Dentre os vários tipos de instrumentos possíveis de serem utilizados para raspagem e alisamento dental temos os manuais, como as "curetas gracey". Entretanto, estes instrumentos necessitam ser afiados para promoverem correta remoção do cálculo e do biofilme dental. Acevedo et. al., ${ }^{2}$ em 2006, comprovaram a eficácia de pedras de afiação tipo arkansas na manutenção do corte e afiação rotineira de instrumentos manuais de raspagem.

O papel real da rugosidade residual da superfície dental na doença periodontal ainda está sem uma resposta efetiva. Sabe-se que a superfície mais rugosa permite maior acúmulo de biofilme, mas também pode facilitar a agregação das células no processo de reparo tecidual na região subgengival. Poggio et al., ${ }^{3}$ em 2009, avaliaram a adesão de Streptococos mutans em diferentes materiais restauradores com diferentes rugosidades superficiais in vitro. Os autores observaram que a composição química e forças eletrostáticas entre material e bactérias foram mais importantes que a rugosidade residual na adesão das bactérias às superfícies.

No entanto, pouco se sabe sobre o grau de lisura ou rugosidade possível de ser alcançado com os instrumentos utilizados na raspagem e alisamento radicular. A dificuldade desta resposta reside na dificuldade de conseguir-se uma metodologia que permita uma avaliação objetiva, tanto quantitativa como qualitativa, desta superfície radicular.

Alguns casos de doenças periodontais necessitam de cirurgias que requerem a utilização de instrumentos rotatórios de alta ou baixa rotação para seccionamentos, plásticas dentais ou simplesmente recontornos dentais. ${ }^{4,5,6,7} \mathrm{O}$ protocolo de utilização destes instrumentos requer um alisamento radicular com uso de cureta manual posterior ao uso das brocas ou pontas rotatórias. Mas são raras as pesquisas comparando a rugosidade após a utilização destas brocas com instrumentos manuais ou vibratórios. ${ }^{8}$

Sendo assim, a proposta desta pesquisa foi verificar o grau de rugosidade possível de ser alcançado utilizando-se cureta manual, ultrassom e ponta diamantada extrafina em caneta de alta e baixa rotação na superfície radicular.

\section{MATERIAIS E MÉtodos}

Foram utilizados para este estudo quarenta dentes humanos extraídos. Esta pesquisa faz parte de uma série de trabalhos para obtenção de título de doutorado. Todos foram submetidos e aprovados pelo Comitê de Ética em Pesquisa Humana da Universidade Estadual Paulista Júlio de Mesquita Filho, campus de Araçatuba - Faculdade de Odontologia, em 4 de junho de 2001, (protocolo N² 2001/1022).

Os dentes foram seccionados e inclusos em cilindro de PVC (Tigre, Brasil), com $2 \mathrm{~cm}$ de altura cheios de resina acrílica quimicamente ativada (JET Clássico, Brasil). Todos os conjuntos dente-resina-PVC sofreram um processo de polimento em uma politriz (MetaServ, 2000). As amostras foram mapeadas com um guia referencial com dimensões que permitissem uma área central mapeada de aproximadamente $9 \mathrm{~mm}^{2}$ e uma seta na lateral esquerda para mostrar o sentido de instrumentação (Figura 1).

As amostras polidas foram divididas aleatoriamente em quatro grupos:

- grupo 1: sem instrumentação;

- grupo 2: instrumentado com cureta gracey manual $n^{\circ}$ 5/6 (Hufriedy);

- grupo 3: instrumentado com ultrassom (Ultrassom Profi II AS Ceramic, ponta 9Q, potência IV e velocidade III; Dabi Atlante, Brasil); 


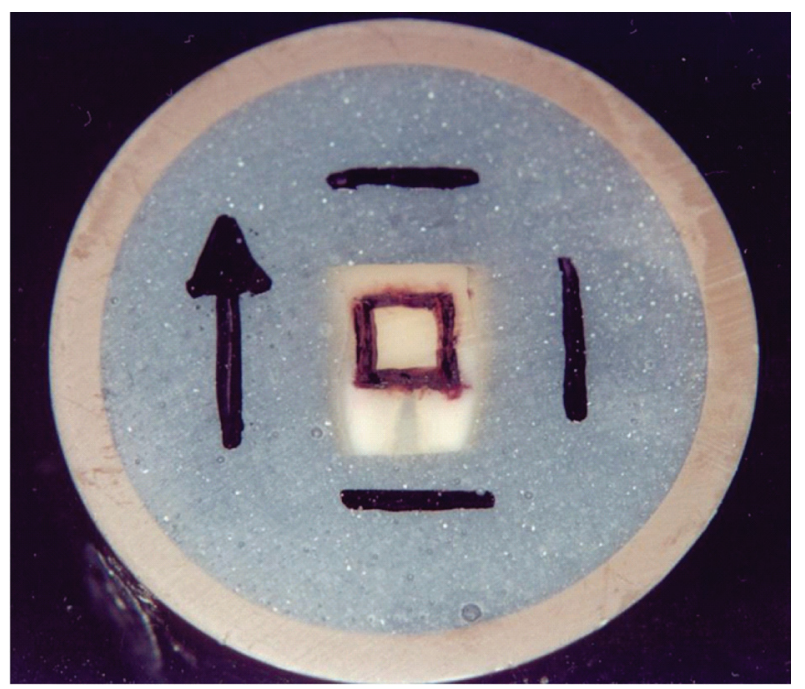

Figura 1 - Raiz inclusa na resina acrílica e mapeada com o guia referencial nas dimensões de $9 \mathrm{~mm}^{2}$ aproximadamente

- grupo 4: instrumentado com ponta diamantada em forma de chama extrafina (3118FF, KG Sorensen Brasil), em caneta de alta rotação (MS 350 Torque, Dabi Atlante - Brasil).

Os grupos 2 e 3 foram instrumentados com 15 movimentos de raspagem, segundo Moreinos. $^{9}$ No grupo 2, os movimentos de raspagem foram realizados no sentido ápice-coronário, com ângulo de trabalho de aproximadamente $45^{\circ}$, seguindo recomendação de Pattison e Pattison. ${ }^{10}$ No grupo 3, os movimentos de raspagem foram realizados no sentido ápice-coronário, com ângulo de trabalho de aproximadamente $0^{\circ}$, sob refrigeração, sem afiação, seguindo recomendações de Flemming et al., ${ }^{11}$ Checchi et al. ${ }^{12}$ e Chaplle et al. ${ }^{13} \mathrm{O}$ grupo 4 foi instrumentado com dez movimentos de raspagem segundo Martins et al. ${ }^{14}$

Todas as amostras foram lidas rugosimetricamente antes e depois da instrumentação, sempre dentro dos $9 \mathrm{~mm}^{2}$, utilizando-se um rugosímetro da marca Kasaka, modelo Surfcorder SE 1700 (Japão), com percurso de leitura de $1,5 \mathrm{~mm}$, cut off de 0,25 $\mathrm{mm}$, velocidade de leitura de $0,1 \mathrm{~mm} /$ segundo e utilizando o Ra (desvio médio aritmético). Foram realizadas três leituras paralelas e três leituras perpendiculares ao sentido de instrumentação, antes e depois da instrumentação. Foram realizadas fotomicrografias em microscopia eletrônica de varredura (modelo JSM-T330A, JEOL, Japão), com aumento de 150 vezes, cujas amostras estavam metalizadas em ouro. Esta metodologia foi desenvolvida por Martins et. al., ${ }^{14}$ em 2001, e aprimorada por Martins et. al. em $2002^{15}$ e $2004^{16}$.

\section{Resultados E discussão}

Inicialmente, foram calculadas as médias das leituras paralelas e perpendiculares separadamente por amostra, antes e depois da instrumentação. Em seguida, foram calculadas as médias paralelas e perpendiculares, separadamente por grupo, antes e depois da instrumentação. Por último, foram calculadas as médias totais, somando as médias paralelas e perpendiculares e dividindo por dois, por grupo, antes e depois da instrumentação. A análise exploratória dos dados revelou que eles apresentaram distribuição normal e variância homogênea. Assim, estes dados foram comparados entre si por meio dos testes " $t$ " pareado e Anova $(\mu=0,05)$. Os resultados estão expostos na Tabela 1 e no Gráfico 1.

Todos os instrumentos testados nesta pesquisa produziram um aumento de rugosidade após a instrumentação, facilmente observados microscopicamente nas Figuras 2, 3, 4 e 5. A única exceção foi na leitura rugosimétrica paralela ao sentido de instrumentação do grupo de ponta diamantada, que não diferiu estatisticamente do controle sem instrumentação. Este fato pode ter ocorrido porque quando o rugosímetro passou paralelo ao sentido de instrumentação na utilização de pontas diamantadas, ele caiu nos sulcos longitudinais produzidos pela broca e imprimiu uma rugosidade menor que a do sentido perpendicular ao sentido de instrumentação. 
Tabela 1 - Tabela mostrando a rugosidade média nos sentidos perpendicular, paralelo e ambos os sentidos juntos, de todos os grupos, depois da instrumentação e comparação entre estes grupos e o grupo controle (valores numéricos das colunas $\mathrm{M}$ e DP em $\mu \mathrm{m})$.

\section{PARALELO}

\begin{tabular}{ccccccccc}
\hline $\mathbf{G}$ & $\mathrm{M}$ & $\mathrm{DP}$ & $\mathrm{G}$ & $\mathrm{M}$ & $\mathrm{DP}$ & $\mathrm{G}$ & $\mathrm{M}$ & $\mathrm{DP}$ \\
$\mathbf{1}$ & $0.0911 \mathrm{~A}$ & 0.0134 & 1 & $0.0955 \mathrm{~A}$ & 0.0154 & 1 & $0.0935 \mathrm{~A}$ & 0.0144 \\
$\mathbf{4}$ & $0.1902 \mathrm{AB}$ & 0.0305 & 4 & $0.3732 \mathrm{~B}$ & 0.0828 & 4 & $0.3125 \mathrm{~B}$ & 0.0255 \\
$\mathbf{2}$ & $0.3977 \mathrm{~B}$ & 0.1080 & 2 & $0.4843 \mathrm{C}$ & 0.0726 & 2 & $0.4659 \mathrm{C}$ & 0.1110 \\
$\mathbf{3}$ & $1.0543 \mathrm{C}$ & 0.2491 & 3 & $1.1495 \mathrm{D}$ & 0.2384 & 3 & $1.0246 \mathrm{D}$ & 0.1218 \\
\hline
\end{tabular}

$\mathrm{G}=$ grupos sem instrumentação $(\mathrm{Co}=$ Controle $)$ ou instrumentados com diferentes instrumentos. $/ \mathrm{M}=\mathrm{Médias} / \mathrm{DP}=\mathrm{Desvio}$ padrão / PARALELO = sentido paralelo de instrumentação $/$ PERPENDICULAR = sentido perpendicular de instrumentação $/$ TOTAL $=$ ambos os sentidos de instrumentação somados e divididos por 2. / Médias seguidas de letras maiúsculas distintas na vertical diferem entre si pela ANOVA e teste de Tukey $(p<0,05)$.

$\mathrm{G} 1$ = grupo controle sem instrumentação / G2 = grupo instrumentado com cureta manual / G3 = grupo instrumentado com ultrassom / G4 = grupo instrumentado com ponta diamantada extrafina em alta rotação / PARALELO = sentido paralelo de instrumentação / PERPENDICULAR = sentido perpendicular de instrumentação $/$ TOTAL = ambos os sentidos de instrumentação somados e divididos por 2. / Médias seguidas de letras maiúsculas distintas na vertical diferem entre si pela ANOVA e teste de Tukey $(p<0,05)$.

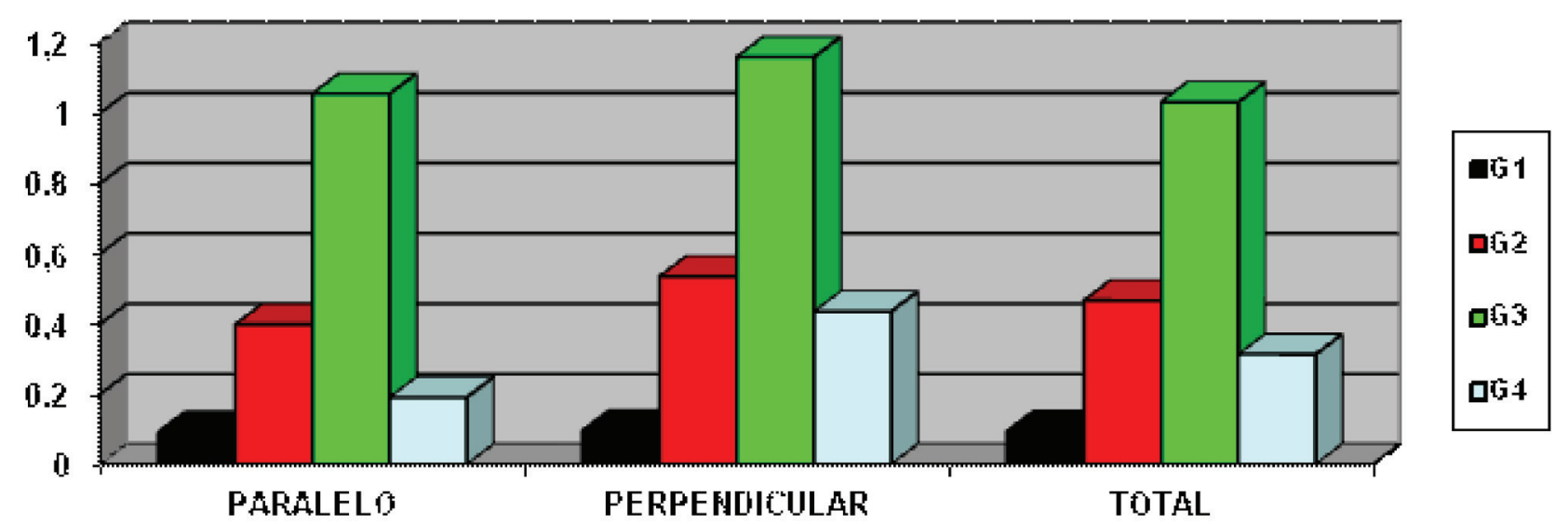

Gráfico 1 - Gráfico mostrando a rugosidade média nos sentidos perpendicular, paralelo e ambos os sentidos juntos, de todos os grupos, depois da instrumentação. (G1 = Controle) (valores numéricos em $\mu \mathrm{m})$.

Daí a possibilidade de diferença entre ambos os sentidos de instrumentação. Nos outros grupos houve uma coerência de resultados em ambos os sentidos de instrumentação, fazendo com que aqui discutamos os resultados baseados somente na média de ambos os sentidos de instrumentação.

Comparando os grupos entre si, pudemos observar que o uso de ponta diamantada em alta rotação apresentou significativo menor aumento de rugosidade em relação ao uso de curetas, e ambos apresentaram significativo menor aumento de rugosidade em relação ao uso de ultrassom. As fotomicrografias em microscopia eletrônica de varredura (MEV) ilustram as formas de relevo constatadas em rugosímetro (Figuras 2, 3, 4 e 5). 


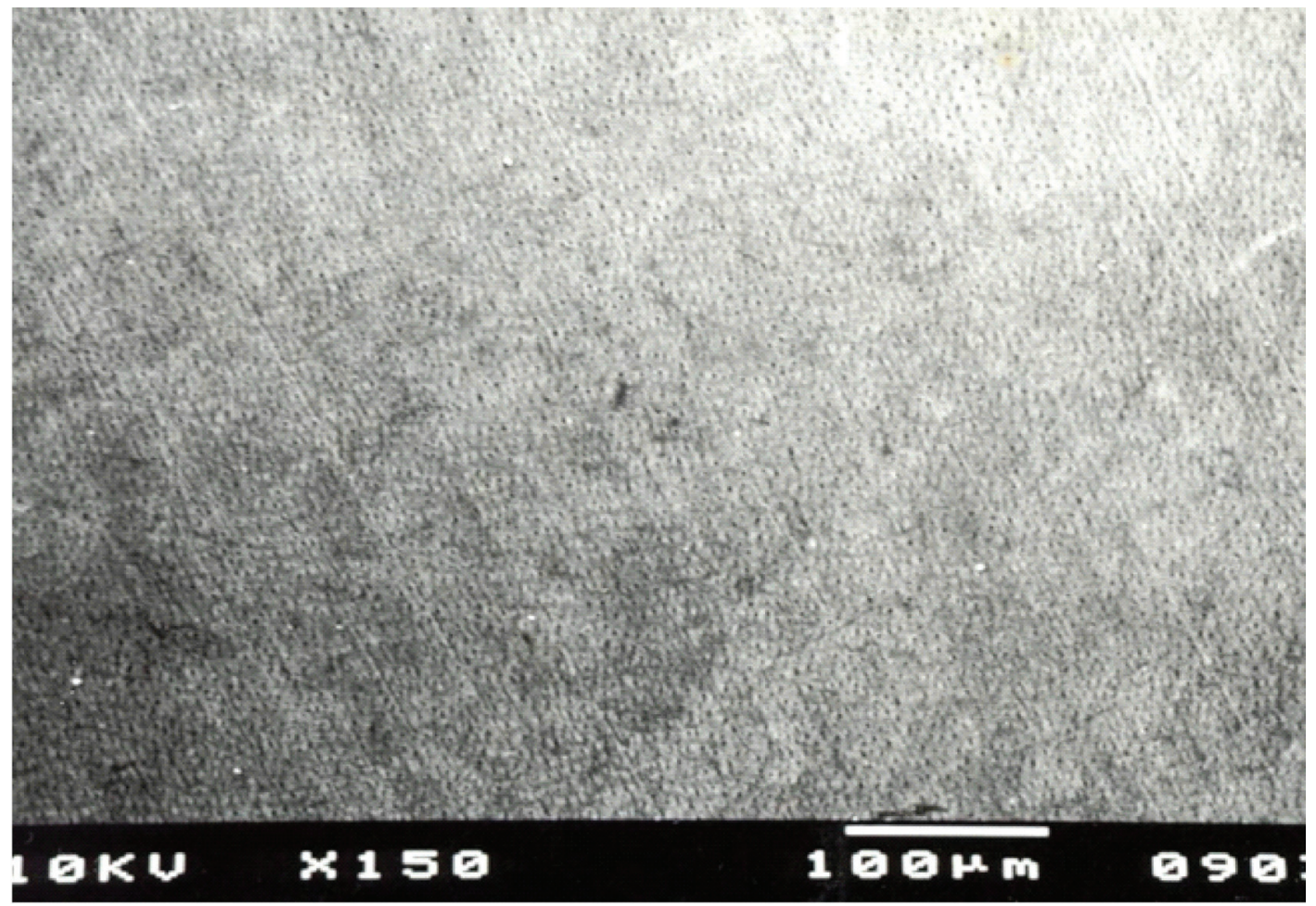

Figura 2- Fotomicrografia eletrônica de varredura do grupo controle (aumento de 150 X)

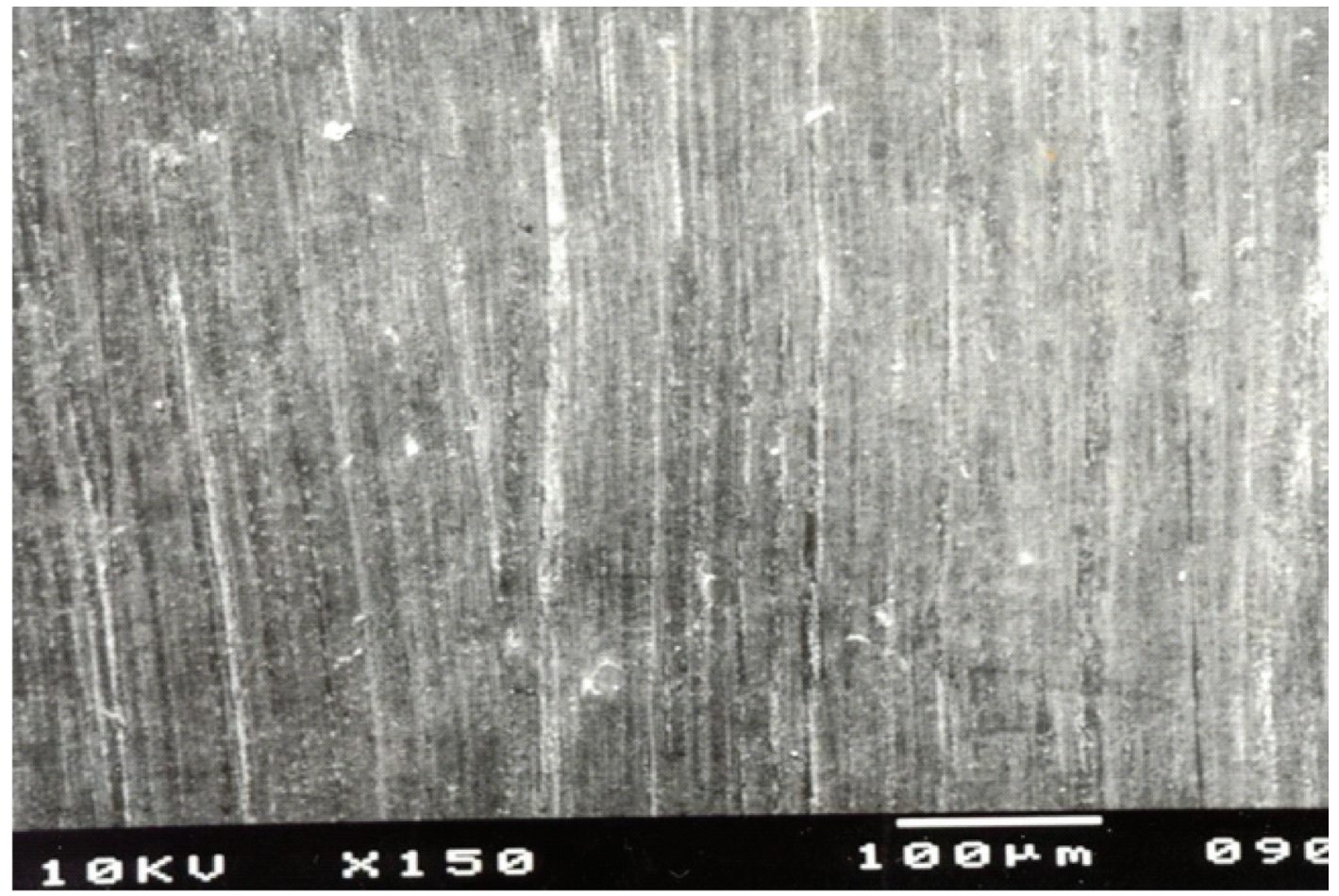

Figura 3 - Fotomicrografia eletrônica de varredura do grupo instrumentado com ponta diamantada em caneta de alta rotação (aumento de 150 X) 


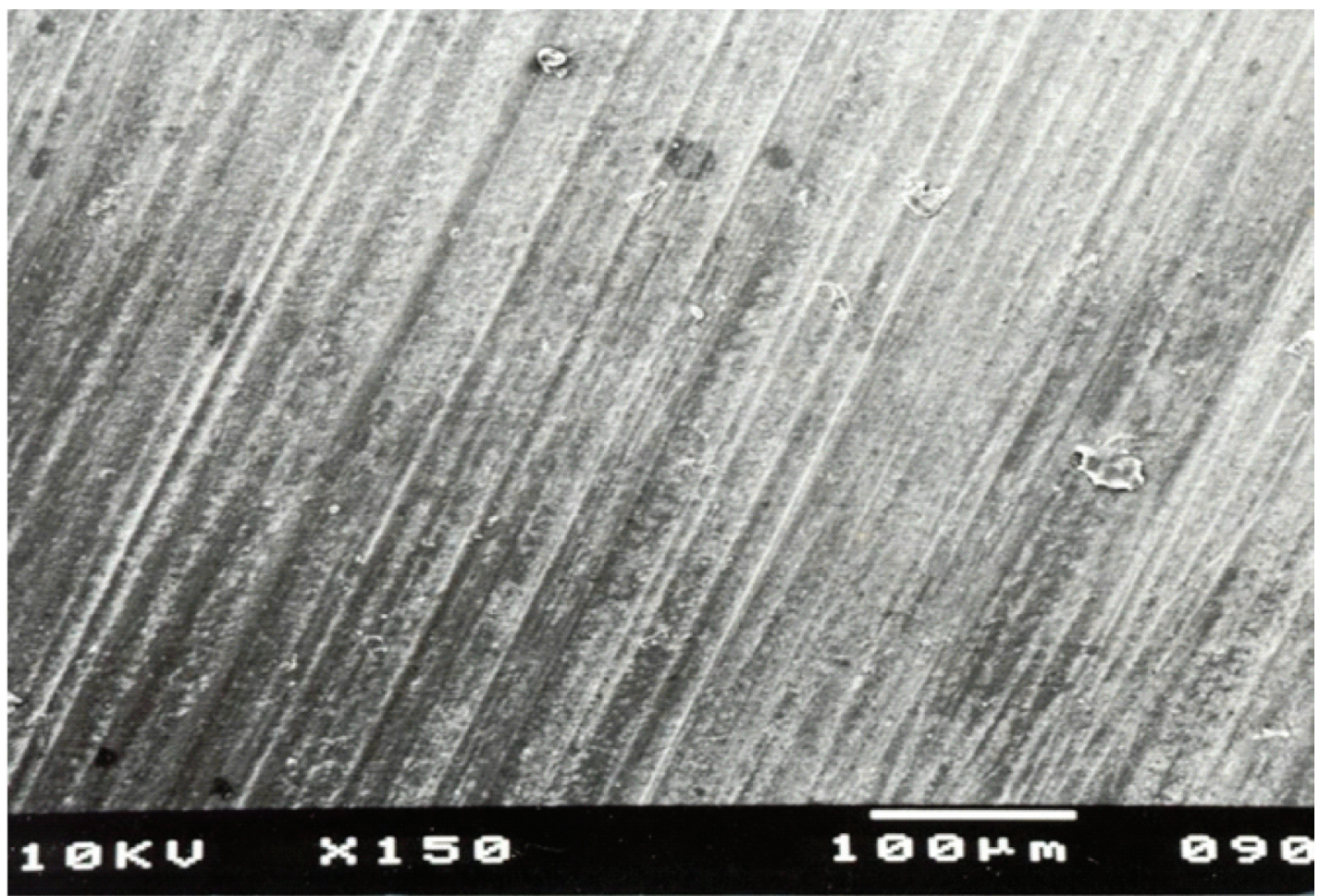

Figura 4 - Fotomicrografia eletrônica de varredura do grupo instrumentado com curetas Gracey n 5/6 (aumento de $150 \mathrm{X}$ )

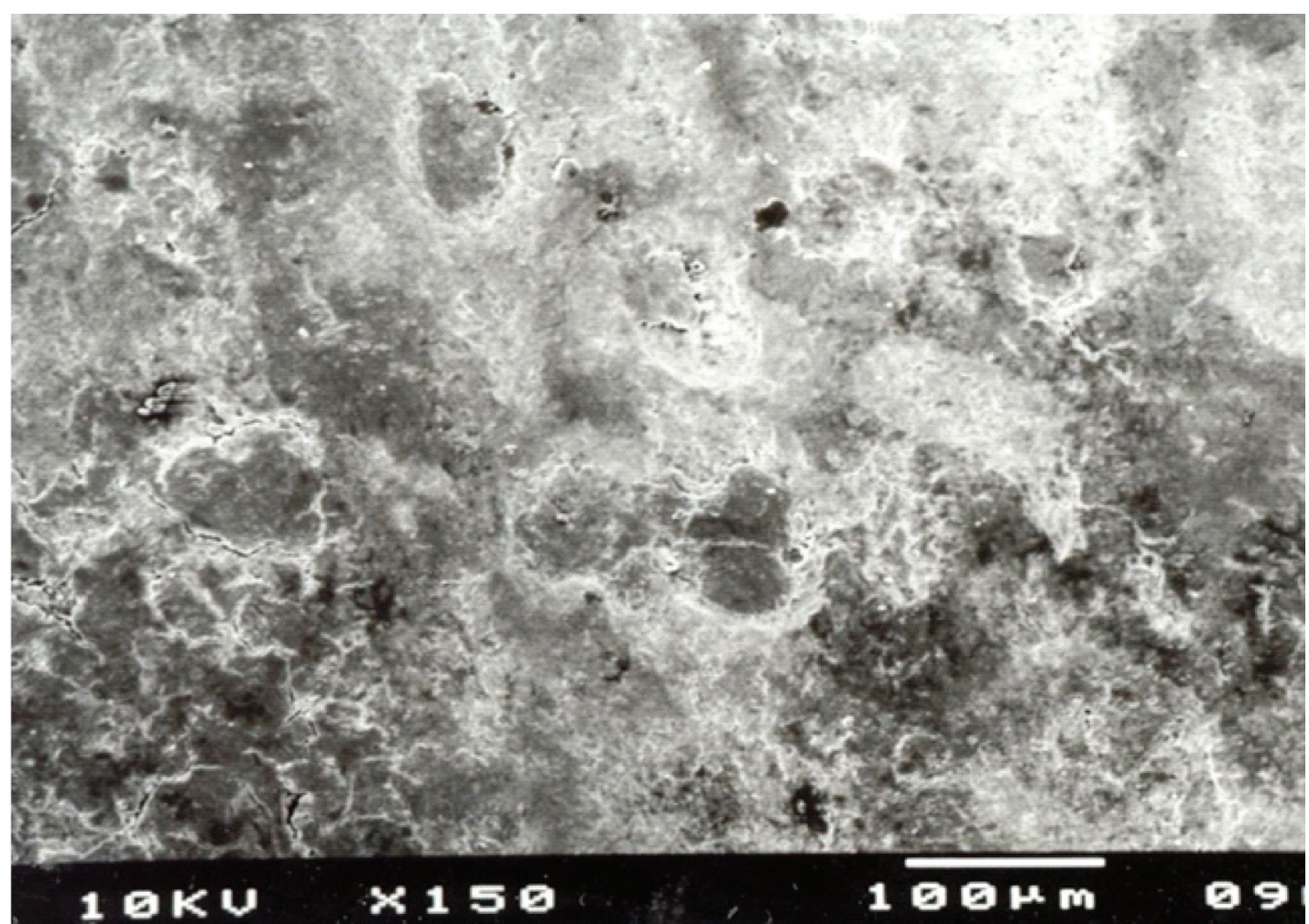

Figura 5 - Fotomicrografia eletrônica de varredura do grupo instrumentado com ultrassom (aumento de $150 \mathrm{X}$ ) 
Os resultados estão de acordo com Allen e Rhoads, ${ }^{17}$ que observaram menor rugosidade com uso de curetas em relação ao ultrassom, apesar de estes autores utilizarem metodologia diferente apenas com MEV. Outros autores obtiveram os mesmos resultados utilizando MEV na metodologia, em anos posteriores. ${ }^{18,19,20}$

Belting e Spjut ${ }^{21}$ observaram a perda de estrutura radicular durante a utilização de instrumentos de raspagem periodontal por meio de MEV. Os resultados mostraram que o ultrassom promoveu menor perda de estrutura dentária que o uso de curetas, mas isto não garantiu menor rugosidade. Nesta pesquisa, os dados foram obtidos pelo uso de rugosímetro, e não de $\mathrm{MEV}$, sendo esta uma avaliação menos subjetiva e traduzindo a rugosidade real da superfície radicular.

Entretanto, Kawashima et al., ${ }^{22}$ em 2007, analisaram a rugosidade residual, a perda de cemento radicular e o cálculo residual após instrumentação periodontal realizada in vivo, e depois extraindo os dentes para análise em MEV. Os autores observaram o uso de dois tipos de raspadores de ultrassom piezoelétrico e de cureta manual. Observaram que o uso de ultrassom produziu superfície radicular mais lisa e com menor perda de estrutura radicular que o uso de curetas. Em relação ao cálculo residual, todos foram semelhantes. Estes resultados são contrários aos obtidos neste trabalho, entretanto, durante a metodologia, os autores não controlaram o tempo de instrumentação e utilizaram metodologia subjetiva de avaliação de rugosidade residual.

Utilizando metodologia com rugosímetro para medição da rugosidade, Kerry ${ }^{23}$ observou que os grupos instrumentados com curetas mostraram menor rugosidade residual que os grupos instrumentados com ultrassom, sendo estes resultados iguais ao do trabalho exposto.

De forma semelhante, Rosenberg e Ash ${ }^{24}$ pesquisaramarugosidadeapós instrumentação periodontal, mas realizando a instrumentação clinicamente, e depois extraindo os dentes para análise. Os resultados mostraram que o uso de curetas manuais promoveu maior lisura de superfície que o uso de ultrassom, semelhante ao resultado obtido. $O$ dado interessante desta pesquisa foi que o uso de ultrassom promoveu uma rugosidade que não diferiu do dente controle sem instrumentação.

Ainda utilizando o rugosímetro para medição rugosimétrica, Schlageter et al. ${ }^{25}$ observaram que o uso de pontas diamantadas finas produziu superfícies radiculares menos rugosas, diferindo estatisticamente do uso de curetas, que produziram superfícies mais rugosas. Entretanto, estas produziram superfícies menos rugosas do que com o uso de ultrassom. Apesar de os autores realizarem a instrumentação clinicamente, depois extraírem os dentes e não padronizarem os movimentos de instrumentação nem a rugosidade inicial antes da instrumentação, os resultados foram semelhantes aos obtidos nesse estudo.

Mesmo utilizando metodologia com rugosímetro, mas contrário aos resultados deste trabalho, Martins et al, ${ }^{14}$ em 2001, observaram que o uso de curetas manuais produziram superfícies radiculares menos rugosas que com o uso de pontas diamantadas extrafinas em alta rotação. Esta diferença é atribuída ao fato de estes autores não padronizarem a rugosidade antes da instrumentação, mostrando, desta forma, que a cureta pode ser mais efetiva que as pontas diamantadas extrafinas na remoção dos detritos, mas não produzirem, necessariamente, menor rugosidade residual. Apesar disso, estes autores também observaram que o uso de ultrassom produz superfícies radiculares mais rugosas que o uso de curetas e diamantadas extrafinas em alta rotação, semelhante aos resultados aqui obtidos.

Martins et. al., em $2002^{15}$ e em 2004, ${ }^{16}$ observaram que o uso de instrumentos de 
raspagem periodontal promoveu aumento significativo na rugosidade radicular quando comparado às superfícies previamente lisas, com resultados semelhantes à pesquisa realizada.

Ribeiro et. al., ${ }^{26}$ em 2006, avaliaram a superfície radicular utilizando exatamente a mesma metodologia de nosso estudo, isto é, utilizando rugosímetro para avaliar a rugosidade residual. Os autores observaram que o uso de curetas produziu superfícies menos rugosas que o uso de aparelho de ultrassom para raspagem radicular, concordando com os resultados observados.

Entretanto, Vastardis et al., ${ }^{27}$ em 2005, analisaram a rugosidade radicular e perda de estrutura radicular utilizando MEV para espessura dentinária perdida e rugosímetro para verificar a rugosidade. Os autores instrumentaram a superfície radicular com controle de quantidade de movimentos de raspagem (10, 20 e 30 movimentos) e com uso de ultrassom e ponta sem corte, ultrassom e ponta diamantada e cureta manual. Os autores observaram que o uso de ultrassom com ponta sem corte e curetas manuais apresentaram a menor rugosidade residual e menor perda de estrutura dental, sem diferença entre ambos. Observaram também que o uso de ultrassom com ponta diamantada promoveu maior perda de estrutura dental e maior rugosidade estatisticamente significante. Esta diferença de rugosidade residual pode ser atribuída ao fato de os autores realizarem maior quantidade de movimentos, e sua análise final foi realizada com o grupo de trinta movimentos de raspagem. Nesta pesquisa, sofreram apenas 15 movimentos de raspagem e, portanto, não houve possibilidade de comparação entre os estudos realizados.

Autores como Abed et al., ${ }^{28}$ em 2007, compararam o uso de laser e curetas manuais para raspagem e alisamento dental, avaliando a topografia da superfície dental com uso de MEV. Os autores observaram que o uso de curetas manuais promoveu menor rugosidade residual, mesmo utilizando MEV para análise da superfície dental. Achados semelhantes foram observados por Hakki, et al. ${ }^{29}$ em 2010. Entretanto, Noori et al., ${ }^{30}$ em 2008, analisaram o uso de aparelho de ultrassom e laser para raspagem e alisamento dental e observaram que o uso de laser produziu menos rachaduras que o uso de ultrassom, mas este produziu menos crateras na superfície radicular. Os autores fizeram a análise da superfície radicular com MEV, de modo semelhante aos autores anteriores, sendo os resultados bastante subjetivos.

Sabe-se que a rugosidade dentária pode propiciar maior acúmulo de biofilme e detritos alimentares nos dentes, promovendo reinfecção periodontal. A grande dificuldade é analisar qual instrumento é capaz de remover o cálculo dentário com a menor rugosidade residual possível. Com este estudo, pode-se comparar a rugosidade residual com uso de diferentes instrumentos para raspagem dental. Os resultados indicaram que, após uso de ultrassom, se faz necessário uso de curetas manuais para alisamento dentário, porém, após o uso de ponta diamantada extrafina durante a reanatomização dental, não é necessário o uso de curetas manuais para alisamento dental.

Sugerem-se mais estudos sobre rugosidade residual após instrumentação periodontal utilizando os diversos tipos de instrumentos para este fim. Também se acrescenta a necessidade de desenvolvimento de uma metodologia efetiva, com menores possibilidades de falhas subjetivas, na avaliação da rugosidade residual. Outros pontos importantes a serem estudados para avaliar a efetividade e segurança de uso de diferentes instrumentos periodontais são sobre a capacidade de remover detritos e cálculos da superfície dental com menor desgaste de estrutura dental sadia. Para este tipo de análise, devem-se desenvolver metodologias 
seguras e efetivas para então responder à grande questão: qual instrumento periodontal remove mais cálculo e detritos da superfície dentária, promovendo menor rugosidade residual com maior segurança de não remover estrutura dentária sadia?

\section{Conclusões}

De acordo com os resultados desta pesquisa científica, concluiu-se que a ação de todos os instrumentos nela estudados promoveu aumento da rugosidade radicular quando comparado à superfície alisada e polida.

O uso de cureta manual produziu rugosidade radicular maior que o uso de ponta diamantada extrafina em alta rotação, mas menor que o uso de ultrassom, que produziu a maior rugosidade radicular. Sendo assim, não há necessidade de alisamento radicular com uso de curetas manuais após uso de pontas diamantadas extrafinas. Entretanto, há necessidade de alisamento radicular com curetas manuais após o uso de aparelho de ultrassom.

\section{REFERÊNCIAS BIBLIOGRÁFICAS}

1. Copulos $T A$, et al. Comparative analysis between a modified ultrasonic tip and hand instruments on clinical parameters of periodontal disease. $J$ Periodontol, 1993, Aug.; 64(8):694-700.

2. Acevedo RAA, Cardoszo AKV, Sampaio JEC. Scanning electron microscopic and profilometric study of different sharpening stones. Braz. Dent. J, 2006; 2(1):237-42.

3. Poggio C, Arciola CR, Rostil F, Scribante A, Saino E, Visai L. Adhesion of Streptococcus mutans to different restorative materials. Int $\mathrm{J}$ of Art Organs, 2009; 32(9):671-77.

4. Bodecker CF. The difficulty of completely removing sub-gingival calculus. J Am Dent Assoc, 1943; 30-I(10):703-8.

5. Caffesse RG, Sweeney PL, Smith B. A Scaling and root planning with and without periodontal flap surgery. J Clin Periodontol, 1986, Mar.; 13(3):205-10.

6. Crespi R. et al. Topographic distribution of sub- gingival plaque along root surfaces of human periodontally diseased teeth. A descriptive study. J Clin Periodontol, 1996, Jul.; 23(7):698703.

7. Aspriello SD, Piemontese P, Levrini L, Sauro L. Ultra morphology of the root surface subsequent to hand-ultrasonic simultaneous instrumentation during non-surgical periodontal treatments. An in vitro study. J of Appl Or Scien, 2011; 19(1):110-23.

8. Chace R. Methods and values of tooth planning in periodontal therapy. J Periodontol, 1961, Jul.; 32(3):233-36.

9. Moreiros M. Contribuição ao estudo da superfície do cemento dentário humano. Após raspagem subgengival. (Comparando o uso de instrumentos manuais com os instrumentos ultrassônicos). Rev Bras Odontol, 1977, jan.abr.; 34(1-2):27-37.

10. Pattison GL, Pattison AM. Instrumentação em periodontia: orientação clínica. São Paulo: Medicina Panamericana, 1988.

11. Fleming TF, et al. The effect of working parameters on root substance removal using a piezoelectric ultrasonic scaler in vitro. J Clin Periodontol, 1998 Feb.; 25(2):158-63.

12. Checchi L, Pelliccioni GA, Dachille C. Sharpening of ultrasonic scalers. J Clin Periodontol, 1991, Aug.; 18(7):505-7.

13. Chapple ILC et al. Effect of instrument power setting during ultrasonic scaling upon treatment outcome. J Periodontol, 1995, Sep.; 66(9):75660.

14. Martins EOB, Sallum AW, Consani S, et al. Avaliação da rugosidade radicular após instrumentação periodontal. Rev Periodontol, 2001, mar.; 10(2):36-44.

15. Martins EOB, Sallum AW, Sallum EA; Martins F, Adabo GL. Análise da rugosidade radicular produzida pelo uso de instrumentos sônicos e ultrassônicos. Estudo in vitro. Rev Periodontol, 2002, dez.; Ed. Especial:39-43.

16. Martins EOB, Sallum AW, Sallum EA, Sampaio JEC, Martins F. Análise da rugosidade radicular produzida pelo uso de instrumentos periodontais manuais de raspagem e alisamento dental. Estudo in vitro. Rev de Odontol Bra Centr, 2004; XII:50-4. 
17. Allen EF, Rhoads RH. Effects of high speed periodontal instruments on tooth surface. J Periodontol, 1963 Jul.; 34(4):352-56.

18. Hunter RK, O'Leary TJ, Kafrawy AH. The effectiveness of hand versus ultrasonic instrumentation in open flap root planning. $\mathrm{J}$ Periodontol, 1984, Dec.; 55(12):697-703.

19. Kerry GJ. Roughness of root surfaces after use of ultrasonic instruments and hand curettes. J Periodontol, 1967 Jul.-Aug.; 38(4):340-46.

20. Wilkinson RF, Maybury JE. Scanning electron microscopy of the root surface following instrumentation. J Periodontol, 1973, Sep.; 44(9):559-63.

21. Belting CM, Spjut PJ. Effects of high- speed periodontal instruments on the root surface during subgingival calculus removal. J Am Dent Assoc, 1964, Nov.; 69(5):578-84.

22. Kawashima $H$, Sato $S$, Kishida M, Ito K. A comparison of root surface instrumentation using two piezoelectric ultrasonic scalers and a hand scaler in vivo. J Periodont Res, 2007; 42:90-5.

23. Kerry GJ. New method for viewing root surfaces. J Periodontol, 1975, Nov.; 46(11):673-6.

24. Rosenberg RM, Ash Jr MM. The effect of root roughness on plaque accumulation and gingival inflammation. J Periodontol, 1974, May; 45(3):146-50.

25. Schlageter L, Rateitschak-Pluss EM, Schwarz, JP. Root surface smoothness or roughness following open debridement. An in vivo study. J Clin Periodontol, 1996, May.; 23(5):460-4.

26. RibeiroFV, Casarin RCV, Nociti JuniorFH, Sallum EA, Sallum AW, Casati MZ. Comparative in vitro study of root roughness after instrumentation with ultrasonic and diamond tip sonic scaler. J Appl Oral Sci, 2006, Apr.; 14(2):124-29.
27. Vastardis S; Yukna RA, Rice DA, Mercante D. Root surface removal and resultant surface texture with diamond-coated ultrasonic inserts: an in vitro and SEM study. J Clin Periodontol, 2005, May.; 32(5):467-73.

28. Abed AM, Tawakkoli M, Dehchenari MA, Gutknecht N, Mir M. A comparative SEM study between hand instrument and Er: YAG laser scaling and root planning. Lasers Med Sci, 2007; 22:25-9.

29. Hakki SS, Berk G, Dundar N, Saglam M, Berk $N$. Effects of root planning procedures with hand instrument or erbium, chromium:yttriumscandium-gallium-garnet laser irradiation on the root surfaces: a comparative scanning electron microscopy study. Lasers in Medical Science, 2010; 25:134-43.

30. Noori ZT, Fekrazad R, Eslami B, Etemadi A, Khosravi SE, Mir M. Comparing the effects of root surface scaling with ultrasound instruments and Er,Cr:YSGG laser. Lasers Med Sci, 2008; 23:283-7.

Endereço para correspondência:

Eleonora de Oliveira Bandolin Martins

Av. Melício Machado n. 3548, Lote 35;

Bairro Aruana; CEP: 49037-440; Aracaju, SE.

E-mail: eleonoramartins2@hotmail.com

Submetido: 1-2-2014

Aceito: 5-5-2014 